\title{
EDITORIAL: AMAZÔNIA: 10 ANOS DEPOIS DE CLÁUDIO PERANI
}

\author{
A Amazônia exige de nós um diálogo constante com as outras \\ culturas; \\ um diferente conceito de território e ambiente; \\ um diferente conceito de natureza; \\ um diferente conceito de relações; \\ um diferente conceito de propriedade; \\ um diferente conceito de produção \\ (Cláudio Perani).
}

Ao contrário do que pensava Cláudio Perani sobre a Amazônia, o Estado e as classes dominantes brasileiras veem a Amazônia sob a ótica do capital. A julgar por seus projetos e ações, estão empenhados em transformar a maior floresta tropical do mundo em propriedade privada de pecuaristas, mineradoras, hidrelétricas e investidores endinheirados de vários tipos. Para isso, evidentemente, precisam subjugar os povos e culturas com quem Perani propunha o diálogo constante e a quem dirigiu, ao chegar à região, sua atenção político-social e pastoral. Dez anos depois de sua morte, compreender a Amazônia continua a exigir, talvez mais que antes, prestar atenção, em meio à floresta, ao caminho do dinheiro, que, em geral, coincide com o caminho do sangue.

Desde que Michel Temer está no poder, há um assassinato por conflito de terra a cada seis dias na Amazônia Legal. E a tendência é de crescimento. Conforme o Atlas de Conflitos na Amazônia 2017, lançado pela Comissão Pastoral da Terra (CPT) com o apoio da Rede Eclesial Pan-Amazônia (REPAM), 76 pessoas foram assassinadas na Amazônia por conflitos de terra desde que Dilma Rousseff (PT) foi tirada da presidência por um impeachment com base legal inventada (pedalada fiscal). A violência na região já era alta nos governos anteriores, mas piorou muito e aceleradamente no desgoverno Temer. Em 2016, houve 48 homicídios (19 ainda com Dilma). No país inteiro, ocorreram 61 mortes por conflitos agrários nesse ano. Em 2017, segundo a CPT, foram 71 assassinatos, sendo que a Amazônia concentrou cerca de $80 \%$ do total.

Na região, desde o assassinato da missionária Dorothy Stang, em 2005, a trilha do sangue indica que os assassinatos estão diretamente ligados à conversão da floresta em propriedade privada. Há uma conexão evidente entre grilagem, desmatamento e mortes por conflitos de terra. Se há grilagem, há desmatamento, pais da escravidão moderna. É isso que 
se expande na Amazônia neste momento. Diferente das relações sociais e conceito de propriedade desejadas por Perani.

O atalho da lei talvez seja o mapa das trilhas sinistras do dinheiro e do sangue. $\mathrm{O}$ programa Terra Legal é um marco no processo de legalização da grilagem na Amazônia. Criado no segundo governo Lula através de Medida Provisória (depois Lei 11.977/2009) a pretexto de regularizar imóveis em terras públicas com até 1.500 hectares e com ocupação anterior a dezembro de 2004, na prática, serviu para regularizar a grilagem praticada pelos grandes. Na época, foi apelidado de "MP da Grilagem" e, depois, de "Lei da Grilagem".

Os números ajudam a evidenciar os objetivos: os pequenos eram quase $90 \%$, mas ocupavam menos de $19 \%$ do território; já os grandes eram menos de $6 \%$, mas ocupavam $63 \%$ do território. Para os pequenos, a lei anterior era capaz de solucionar a situação e corrigir injustiças, pois autorizava a titulação de até 500 hectares para quem trabalhasse e residisse na terra. Por isso, a Medida Provisória (e a Lei que se seguiu) foi pensada para legalizar a grilagem.

Com Temer, a grilagem foi ampliada com a Lei 13.465/2017. Sob o mesmo argumento de antes - regularizar posses de boa-fé -, permitiu aos grileiros de terras públicas regularizarem seus "grilos", agora, até 2.500 hectares. Simples assim: basta expandir a produção de "laranjas" e os "grilos" são legalizados de 2.500 em 2.500 hectares. Desse modo, o Congresso Nacional e Temer anistiaram grileiros e converteram criminosos em proprietários legais.

Para reafirmar o conceito de natureza desse setor, em todo distinto do que propunha Perani, o governo e próceres da bancada ruralista, mais uma vez, propõem legalizar o "grilo", também, onde hoje existem unidades de conservação ambiental. Atualmente, isso é juridicamente impossível. Por isso, pressionam cada vez mais para reduzir o tamanho dessas unidades de conservação ou mesmo desprotegê-las. Enquanto isso, apostam na estratégia de ocupá-las e desmatá-las. Seguindo esse ideário, Temer e os ruralistas patrocinam um Projeto de Lei pelo qual 354 mil hectares deixem de ser Floresta Nacional, uma categoria legal mais protegida, para se tornarem Área de Proteção Ambiental (APA), isto é, áreas onde seriam legalmente permitidas atividades como agricultura e pecuária. Enfim, o Estado se esforça para promover a legalização do crime e expor os povos tradicionais à violência do latifúndio. 
Voltando a atenção para o capital, pode-se ver o boi pavimentando a trilha do dinheiro. Estudos revelam a existência de 400.000 fazendas pecuárias na Amazônia, um território mais de boi do que de gente. Eram 85 milhões de cabeças em 2016, contra uma população humana de 25 milhões de habitantes, ou cerca de três bois por pessoa. No extremo, em São Félix do Xingu, essa proporção chega a 18 por 1. São 99 empresas, com 128 frigoríficos, responsáveis por $93 \%$ do abate desse gado (equivalente a $40 \%$ do rebanho nacional), ou 12 milhões de cabeças por ano transformadas em bifes e outros cortes.

Desastradamente, o conjunto desses frigoríficos, operando a plena capacidade, demandaria uma área de pasto de 68 milhões de hectares, algo superior às pastagens existentes na região, indicando que o capital gerará mais desmatamento no futuro. Para o Instituto do Homem e Meio Ambiente da Amazônia (Imazon), "se entre 2016 e 2018 a taxa de desmatamento recente se repetir, 90\% das novas perdas de floresta estarão dentro da área de influência de compra de 128 frigoríficos". Por isso, o "boi de desmatamento", como é chamado esse gado, levou à formulação de um Termo de Ajuste de Conduta (TAC) proposto pelo Ministério Público Federal (MPF) aos frigoríficos, desde 2009, buscando fazer com que que essas empresas sejam obrigadas a fiscalizar a origem do gado que compram e barrem o boi-mercadoria que derruba a floresta. Todavia, sem sucesso. Afinal, como o capital dispensaria a mercadoria que ampliadamente o reproduz? Tanto que a análise das regiões de influência de compra dos 128 frigoríficos demonstrou que nelas se encontram $88 \%$ do desmatamento ocorrido na Amazônia entre 2010 e 2015, abrangendo a quase totalidade das áreas embargadas pelo Instituto Brasileiro do Meio Ambiente e dos Recursos Naturais Renováveis (Ibama).

Mantida a primazia política desse capital, as próximas áreas a serem desmatadas estão claramente localizadas. Isso porque o mapa de probabilidade de desmatamento cartografado pelo Imazon coincide em 90\% com as zonas de influência de compras desses frigoríficos.

Negando essas relações de propriedade e com a Natureza, na trilha amazônica que Perani se propôs a caminhar, estão os povos tradicionais, os que não veem a terra como propriedade, mas como reprodução da vida. Todavia, justamente eles, os indígenas, ribeirinhos, quilombolas e camponeses são os que estão sendo vitimados por esse processo de transformação da nossa floresta tropical em propriedade privada do capital. 
Ao longo dos artigos publicados nesta edição especial, alguns dos quais pouco conhecidos ou de difícil acesso, Perani partilha suas reflexões acerca da Amazônia, bem ao seu estilo: ao mesmo tempo sintético e questionador, objetivo e inspirador. Antes que produzidos para ambientes acadêmicos, são textos oriundos das inúmeras assessorias, palestras, debates e cursos de formação realizados por ele no decorrer de sua duradoura presença solidária junto aos povos amazônidas.

Para início de conversa, ele chama a atenção reiteradas vezes para a necessidade de conhecermos a Amazônia para além do estereótipo de lugar de grandes riquezas, ricas tradições folclóricas e paisagens exuberantes, o qual, em que pese ser verdadeiro, impõe-se geralmente em detrimento do mais importante: seus habitantes, suas culturas e iniciativas. Atravessa o seu pensamento a convicção profunda da singularidade, vitalidade e criatividade da região, "de onde poderão surgir respostas aos mais graves problemas com que se debate a sociedade mundial". Migrando o raciocínio para o mundo eclesial, afirma que "a Igreja de palha pode fornecer soluções criativas para todas as Igrejas-irmãs".

Segundo ele, é preciso quebrar a noção de uma região atrasada, com grandes riquezas mas incapaz de administrá-las, o que significa dizer: sempre dependente e sem autonomia própria. Diante da visão de uma Amazônia que precisa do resto do mundo, Perani provoca: não seria exatamente o contrário?

Para ilustrar tal concepção, fiquemos apenas num caso concreto. Sem negar a grande contribuição aportada pelo Movimento dos Sem Terra (MST) à organização dos pequenos camponeses em diversas regiões da Amazônia, ele alerta para o fato de que, em alguns lugares, "isso pode ter sido um erro porque os camponeses do Sul não conseguem produzir de acordo com a vocação da floresta. Eles estão acostumados a derrubar para plantar". Afortunadamente, isso tem mudado, como o demonstra a experiência da Rede de Agricultores Tradicionais da Amazônia (REATA), que reúne diversas famílias de agricultores para fortalecer a sua organização e aprender com os povos indígenas e ribeirinhos como cultivar alimentos sem destruir a floresta: "o MST tem aprendido muito com a Amazônia e tem levado esses ensinamentos para outras regiões do Brasil".

Outra importante consideração de Perani diz respeito à constatação de que o atual modelo de desenvolvimento fracassou: "a riqueza aumenta sempre mais e, com ela, também a pobreza de muitos". Importado do Ocidente e corroborado, inclusive, por muita gente que se considera de esquerda, tal conceito de desenvolvimento "visa à produção e ao lucro, 
criando, em todo lugar, sociedades de trabalhadores e consumidores. Resultado: as desordens sociais e a destruição ambiental aumentaram". Seu olhar acurado para a Amazônia localizou precisamente o problema: o agronegócio, a mineração e a biopirataria estão roubando até a água; os projetos energéticos e viários das grandes rodovias e hidrovias são concebidos para favorecer interesses externos; o trabalho escravo, o narcotráfico, a militarização e a violência só fazem crescer.

Ele tinha ciência de que a superação deste paradigma representa um desafio imenso e complexo, um "caminho muito comprido", mas estava igualmente convencido da urgência em pensar e realizar outro tipo de desenvolvimento, "que saiba respeitar e integrar melhor as diferentes culturas". Perani sempre confiou no futuro, via a Amazônia criando estruturas produtivas e sociais próprias, com demandas particulares, e não apenas como uma simples fronteira para a expansão da economia e da população.

Não era do seu feitio apresentar "receitas" ou "fórmulas prontas" de conduta, mas é possível desentranhar de seus escritos um rosário de preciosas observações. Comecemos pelo Perani pastor, que nos oferta uma "Santíssima Trindade" teológica:

a) Deus fala pelas margens.

b) Jesus considera fundamental a sabedoria de vida e iniciação à fé dos pequenos.

c) O Espírito Santo sempre nos precede e abre caminho, agindo antes de nós.

Já o Perani assessor brinda-nos com um decálogo metodológico:

a) É fundamental aprender a arte da escuta e do diálogo.

b) O caminho da inculturação passa por não dizer muitas coisas e repensar o que está na cabeça.

c) Muitas vezes, o povo fala pelo silêncio e se manifesta pelo corpo encurvado sob o peso da opressão.

d) O povo se expressa em cochicho para não ser impedido de falar.

e) Para ouvir os clamores do povo é preciso silenciar e prestar mais atenção.

f) Há que olhar direito e deixar-se descolonizar para poder enxergar as maravilhas que o povo faz. 
g) Quem quer conhecer um povo precisa visitar, ficar um tempo; não é somente passar uma vez e ir embora, é preciso retornar sempre e andar por aí no meio do povo.

h) É preciso viver de igual para igual em nosso estilo de vida pessoal e institucional segundo a causa que defendemos.

i) A evangelização da presença consiste em favorecer a vida e a cultura do povo e, acima de tudo, deixar-se ensinar pela sua sabedoria.

j) O caminho da libertação é sempre difícil, apresentando avanços e retrocesso, mas é um caminho já traçado.

Para mais, somente se deliciando com a escrita mesma de Perani...

Na sequência dos textos autorais do nosso homenageado, seguem artigos que refletem a sua trajetória na Amazônia (e, eventualmente, antes dela ${ }^{1}$ ), seu legado aos movimentos sociais e pastorais católicas na região Norte do país.

Em "Cláudio Perani e o papel da educação popular nos paradigmas de libertação e transformação social na Amazônia", a socióloga Márcia Maria de Oliveira discute o método de formação para a ação social em processos de educação popular. Para a professora da Universidade Federal de Rondônia, o método desenvolvido por Cláudio Perani, em diálogo com Paulo Freire, emprega técnicas que promovem maior participação e envolvimento das lideranças na formação, possibilitando pensar a "eficácia da mudança" que vem das bases, das quais o povo participa de forma efetiva e não é apenas mero espectador ou receptor.

Ressalta que para Perani, a eficácia política da educ(ação) se relaciona mais a favorecer novos tipos de sociabilidade que integram melhor o econômico-político com o cultural, tradições com novidades, espaços e tempos. Como Freire, ele apontava para uma mudança profunda capaz de transformar a sociedade a partir de mulheres e homens, novos portadores de sonhos, utopias e projetos.

\footnotetext{
1 Sobre o período em que Cláudio Perani atuou no Centro de Estudos e Ação Social (CEAS), de Salvador, e, a partir deste, não apenas na Bahia como em vários outros Estados do país, ver a edição especial dos Cadernos do CEAS (número 233, janeiro-junho, 2009).
} 
Com certeza, o artigo é uma contribuição importante ao mesmo tempo à compreensão do método de Cláudio Perani e aos grupos, lideranças e assessorias populares que desejarem refletir sobre sua prática política e formativa junto a novos ativistas e movimentos sociais.

Logo depois, em "Cláudio Perani SJ, profeta da Amazônia: da Equipe Itinerante (1998) à Rede Itinerante da REPAM (2018)", de autoria coletiva dos membros da Equipe Itinerante da REPAM ${ }^{2}$, afirma-se que a região continua sendo considerada uma grande reserva de riquezas a serem exploradas e, ao mesmo tempo, algo de maravilhoso e folclórico a ser admirado. Num caso e no outro, não se considera sua população, menos ainda a personalidade cultural muito forte do seu povo. Noutra perspectiva, a Equipe Itinerante percebe a modernidade do capitalismo na Amazônia, revelando sua cara ainda mais violenta que em outras plagas. E, citando Perani, reconhece que "a Companhia tem uma dívida histórica para com os povos indígenas", pois "de suas fileiras saíram projetos de evangelização nocivos ao índio".

Hoje, não por acaso, não veem outra opção de trabalho evangélico senão pela ótica da justiça e da opção pelos pobres, recentemente reconfirmada pela Companhia de Jesus. Reconhecem, brotando da realidade amazônica, o conflito existente entre explorados e exploradores, definindo-se, enfaticamente, do lado dos injustiçados, não como uma opção pastoral facultativa, mas como uma opção necessária.

Para dar conta dessa missão, a Equipe Itinerante, criada por Perani e atualmente com vinte anos de trajetória, define-se como integrante da REPAM. Essa, por sua vez, aqui é metaforicamente explicada pela imagem da malhadeira ou malha de pescar, equipamento que os ribeirinhos esticam nos rios, com os seus três elementos fundamentais: as boias que a fazem flutuar, os chumbos que a fazem afundar até os peixes e o pano que conecta as boias e os chumbos da malhadeira. Por sua vez, as boias e os chumbos mantêm a malha esticada, evitando que fique enrolada, podendo assim capturar os peixes.

\footnotetext{
2 A Equipe Itinerante é um espaço interinstitucional de serviço aos povos e à Igreja da Pan-Amazônia. Presta um serviço missionário itinerante que tenta complementar os outros serviços da lgreja mais institucionais e inseridos da sua missão na Amazônia, especialmente onde os outros não chegam, onde as feridas estão mais abertas e a vida mais ameaçada. Na atualidade, a Equipe está formada por nove pessoas enviadas por oito instituições.
} 
E quais peças da REPAM corresponderiam aos elementos da malha de pescar? Para os autores, os "entralhos de chumbo", que levam a Rede até o fundo, seriam "uma infinidade de paróquias e pastorais sociais, de comunidades de base e equipes missionárias, de comunidades religiosas masculinas e femininas, de leigos e leigas...", espalhadas pelas entranhas da Amazônia; enquanto as "boias", que dão estabilidade e continuidade à missão, seriam as instituições, a começar pela própria Secretaria da REPAM, que logrou articular importantes organizações na construção da Rede, como o Conselho Episcopal LatinoAmericano (CELAM), a Confederação Latino-Americana de Religiosos (CLAR), o Secretariado Latino-Americano e Caribenho da Cáritas (SELACC) e a Comissão para a Amazônia da Conferência Nacional dos Bispos do Brasil (CNBB); e, finalmente, o "pano de pescar", que seria a própria Rede Itinerante, conectando comunidades e aldeias, o campo e a cidade, dando visibilidade às realidades mais distantes, isoladas, aproximando-as das instituições e inserções. Atuando dessa maneira, a REPAM buscaria facilitar uma (cosmo)visão territorial conectada, geopolítica, desde dentro, com os povos que cuidam da Amazônia e do bem comum (bem-viver) de todos os seus seres.

Noutra perspectiva, coube ao professor de História da Universidade Federal da Bahia (UFBA), Iraneidson Santos Costa, lançar um olhar mais amplo e matizado sobre a trajetória intelectual do homenageado. Em "O que disse Cláudio Perani sobre Karl Marx? (reflexões a partir de um documento inédito)", esse atento pesquisador da trajetória dos jesuítas na sociedade brasileira retoma a relação de Perani com a filosofia do materialismo histórico, o método de análise marxista e o socialismo, em que pese reconhecer o fato deste nunca ter dedicado um texto específico ao tema.

Todavia, a partir de uma carta de 1979, descoberta durante a pesquisa em curso, Cláudio Perani procurou responder a um instigante questionamento advindo do Superior da Sociedade de Jesus: "Um cristão pode adotar a análise marxista, distinguindo-a da filosofia e da política marxista?". Partindo desse problema, o artigo traça o percurso do missivista em direção ao marxismo e entre os marxistas, analisando não apenas o referido documento, como também toda a sua produção intelectual (tese, artigos, entrevistas etc.). Nessa trajetória, ressalta a capacidade de diálogo, de convivência com o diferente, de busca do equilíbrio entre posições conflitantes, fiel ao princípio inaciano de "estar mais disposto a salvar a proposição do outro do que condená-la", mostrando como em diversos escritos ele reconheceu o caráter pedagógico do outro, sobretudo o não-crente. 
Assim, o esforço do autor direciona-se a esclarecer, afinal, o que disse Cláudio Perani sobre Karl Marx. O leitor que não conheceu o padre Perani, certamente se surpreenderá com passagens nas quais afirma que a análise marxista não só lhe permitiu aprimorar o conhecimento da realidade em que vivemos e o caminho da história, mas também aprofundar a sua "interpretação do Evangelho e da prática de Jesus, inspiradora da minha prática hoje", sem, contudo, deixar de apontar o que considerava falhas e insuficiências do marxismo. O artigo deixa evidente que, para Perani, as dificuldades de compatibilizar as práticas cristãs com o marxismo estariam não propriamente nos meios de luta a serem empregados, mas, principalmente, na maneira de se conduzir a luta, "que pode tornar-se antidemocrática, com consequências muito nefastas. Aqui, sem dúvida, está a parte mais questionável".

Este artigo, seguramente, representa uma importante contribuição da pesquisa histórica para uma compreensão mais acurada da prática social e pastoral de Cláudio Perani, tanto na Bahia quanto na Amazônia.

Por sua vez, o cientista social e teólogo Ivo Poletto, em "Padre Perani: profeta do povo", lembra-nos as advertências que ouvia desse jesuíta durante o agravamento das crises sociopolíticas, sempre que o desânimo político afligia o autor: "Ainda ouço sua voz estridente e seu sorriso quase irônico: você está esquecendo que os dominadores não terão a última palavra? Lembre que é junto com o povo empobrecido que está a chave da história, a permanente possibilidade de futuro".

Poletto relembra as parcerias de juventude com Perani, suas aproximações e divergências durante o processo de criação da CPT e, também, os tempos de trabalho de Cláudio Perani na região Norte. Enfoca a sua decisão de provocar um processo de articulação de pastorais e movimentos sociais amazônicos em favor da estratégia de "convivência com a Amazônia", inspirado e provocado pelos avanços construídos na Caatinga, com as iniciativas de promoção da convivência com o Semiárido brasileiro. Tentaria uma articulação em favor de iniciativas adequadas ao bioma, que devem ser base para a "Amazônia que a gente quer". Como já percebemos, o ponto culminante dessa iniciativa é, hoje, a formação da REPAM.

Observa, com acerto, que, para a REPAM, será fundamental examinar o quanto e como está contribuindo com o processo de convivência com a Amazônia, porque, sem isso, não haverá crescimento do protagonismo popular; e, sem esse protagonismo, não será nem 
a Igreja, nem outro tipo de instituição que garantirá que a Amazônia continue existindo e sendo a fonte de água para ela própria e para os demais biomas do Brasil e da América do Sul.

Em seguida, José Ricardo Wendling, ex-vereador de Manaus e atualmente deputado estadual pelo Amazonas, rememora em "Cláudio Perani, um Paulo Freire dos Movimentos Sociais" a atuação política cidadã de Cláudio Perani e sua contribuição para a formação de lideranças populares no espaço urbano de Manaus, uma face pouca comentada da trajetória do jesuíta. Registra o autor que "ele foi muito importante na minha caminhada política. Foi inspiração. Deu incentivo. Cobrou".

Aqui, aparece o Cláudio preocupado com os processos político-eleitorais, apoiando candidaturas comprometidas e, principalmente, orientando a formação de consciências críticas para participar das disputas políticas, mas sem se deixar cooptar pelas tentações do espaço institucional.

Encerrando a seção de artigos dessa edição, o professor de Teologia do Instituto de Teologia, Pastoral e Ensino Superior da Amazônia (Itepes) e de Filosofia da Faculdade Salesiana Dom Bosco, Ricardo Gonçalves Castro, que trabalhou com Claudio Perani no Serviço de Ação, Reflexão e Educação Social (SARES), enfatiza, em "Aporias de educação popular nas entrelinhas da práxis educativa de Pe. Cláudio Perani", os contextos e conteúdos retirados da vivência concreta do projeto de ação e reflexão promovido pelo Sares, principalmente nos anos de 2005 a 2010. À luz dessas experiências, enfatiza quatro aspectos fundamentais que nascem do trabalho de equipe do Sares, então coordenado por Perani: os processos políticos na Amazônia; o desafio de elaborar políticas públicas com o povo, de modo organizado e com ética; a valorização da sabedoria popular, base da história dos movimentos sociais na Amazônia.

Lastreado numa visão de identidade antiessencialista, o autor valoriza a convergência histórica das culturas indígena e ibérica, afro e nordestina, que teriam constituído um contexto pluricultural e intercultural particular, com convergências e divergências, porém, marcado por um dinamismo relacional em esforço contínuo para se reconhecerem, para eliminar preconceitos e estereótipos.

Outra perspectiva posta em foco neste artigo provém das teorias pós-coloniais, propugnando uma política de resistência transformacional para formas injustas e desiguais das práticas coloniais, adotando uma visão política pluralista e anti-hegemônica. 
A partir dessa perspectiva, as características históricas dos povos da Amazônia resultariam da confluência, das releituras feitas nas práticas cotidianas, de ritmos, cores, danças, linguagens e experiências do transcendente. Assim, na Amazônia, sociedade, política e religiosidade seriam compostas das contribuições de saberes de origens diversas. O autor, então, propõe-se a conectar essa leitura com a análise da realidade amazônica feita por Perani, vinculando alguns princípios que fundamentavam a prática educativa do Sares à complexidade cultural da formação identitária abordada pelas lentes da teoria pós-colonial. Para dialogar esse intento com a leitura de Perani, Ricardo Castro recorre a aspectos da metodologia de trabalho popular por ele desenvolvidas.

Desse modo, proposições como fazer o possível com as pessoas e recursos disponíveis, valorizar as práticas cotidianas, priorizar os processos que conduzem à ação, sonhar a utopia mas trabalhar com o que se tem na realidade, manter contato com a realidade da vida das pessoas, a conversa gratuita com os moradores das localidades, ação e reflexão realizadas entre teorias e práticas, entre a biblioteca e contato com o povo, são aproximadas aos pressupostos da pós-colonialidade.

Ao leitor, caberá fornecer uma resposta à questão: se cabe ou não ler Cláudio Perani com as lentes das teorias pós-coloniais ou, ainda, como sugere o autor, se a construção de uma sociedade pós-colonial ocorrerá através de processos democráticos cotidianos, baseados no melhoramento da comunicação, do diálogo e do saber analisar as causas dos problemas e planejar e agir juntos em equipes, organizações e movimentos sociais.

Finalizando esta edição, são disponibilizados depoimentos de pessoas que conviveram com Cláudio Perani, dentre os quais destacamos os relatos de Ruben Siqueira (CPT), Ivo Follmann (Universidade do Vale do Rio dos Sinos/Unisinos) e de Dom Sérgio Eduardo Castriani, arcebispo de Manaus.

Joaci de Sousa Cunha (CEAS/UCSal)* Iraneidson Santos Costa (UFBA)**

\footnotetext{
* Coeditor da revista Cadernos do CEAS e realiza estágio pós-doutoral na Universidade Católica do Salvador (UCSal).

** Professor do Departamento de História e do Programa de Pós-Graduação em História da Universidade Federal da Bahia (UFBA).
} 